\title{
Seasonal incidence of pod fly (Melanogromyza Obtusa Malloch) and pod bug (Clavigralla Gibbosa Spinola) in short duration pigeon pea
}

\author{
Anil Kumar Pandey, Ram Keval, Amit Yadav* and C. P. Srivastava \\ Varanasi- 221005 (Uttar Pradesh), INDIA \\ *Corresponding author. E-mail: amitento21@gmail.com \\ Received: January 31, 2015; Revised received: October 14, 2015; Accepted: January 14, 2016
}

Department of Entomology \& Agricultural Zoology, Institute of Agricultural Sciences, Banaras Hindu University,

\begin{abstract}
The present study was aimed at observing the incidence pattern of pod fly and pod bug in pigeonpea ecosystem. The experiment was conducted at Agricultural Research Farm, Banaras Hindu University, Varanasi during the kharif season of the year 2010-11. The short duration pigeon pea was infested with the number of insect pests at various stages of crop growth. Out of which the incidence pattern of pod fly M. obtusa and pod bug C. gibbosa was studied. The first appearance of pod fly $M$. obtusa was noticed in the 42 standard week with a mean population of 0.10 maggot/Plant whose maggot population peaked in 45 standard weeks with a mean population of 0.30 maggot/ Plant during year 2010-11. Similarly the first occurrence of pod bug C. gibbosa was recorded in 40 standard weeks with a mean population of 0.03 larvae/Plant which attained the peak during 44 and 45 standard weeks, in both the week themean population was 0.40 larvae/Plant. The incidence of all the insect pests although declined after attainment of their respective peak, but pod bug were noticed in the field till the harvest of the crop. To undertake an effective IPM strategy in pigeonpea crop, location specific information on occurrence and seasonal dynamics of insect pests is indispensible.
\end{abstract}

Keywords: Pigeon pea, Pod fly, Pod bug, Seasonal incidence

\section{INTRODUCTION}

Pigeon pea [Cajanus cajan (L.) Millsp.] is also known as red gram, arhar, tur in vernacular is the most important delicious pulse of the entire country. After gram, arhar is the second most important pulse crop of India, which contributes about 90 per cent of the world's pigeon pea production. Pigeon pea is one of the most important pulse crop, to be cultivated in 25 countries of the world on 5.8 million ha with 4.4 million tonnes of production, whereas in Asia it is grown in 5.07 million ha and producing 3.07 million tonnes in 2011 (FAO, 2013). In india, pigeon pea cultivated in 4.07 million ha area with a production of 3.27 million tonnes (Anonymous, 2011). Economic loss due to biotic stress factors has been estimated to be \$US 8.48 billion (Arora et al., 2013). The productivity of pigeon pea has not increased considerably during last decade in India. The damage caused by insect pests is one of the major reasons of low productivity. Sachan et al. (1994) have reported that pigeon pea is attacked by nearly 250 species of insect pests worldwide belonging to 8 orders and 61 families though relatively few cause serious yield losses. The key pests of pigeon pea include gram pod borer Helicoverpa armigera (Hubner), legume pod borer Marruca vitrata (Fabricius), tur pod fly Melanagromyza obtusa (Malloch), tur pod bug Clavigralla gibbosa (Spinola), blue butter fly Lampides boeticus
(L.) and plume moth Exlastis atomosa (Walsingham) significantly reduce the crop yield to an extant of 60 to 90\% pigeon pea (Durairaj 2006).

Incidence of these pests in pigeon pea increases with the advancement of crop age and the actual damage to the economic produce takes place after the flowering of the crop. The pod fly and pod bug directly influenced the grain yield of the crop. Although a large number of insect pests were noticed in the vegetative stage of the crop, they hardly had any significant influence on the yield performance. In a survey conducted by ICRISAT, M. obtusa (Malloch) was reported to damage 22.5 per cent pigeon pea pods in north India, 21 per cent in central India and 13.2 per cent in South India (Lateef and Reed, 1981), where as the pod borer damage was reported to be 29.7 per cent in North-West Zone, 13.2 per cent in North Zone 24.3 per cent in Central Zone and 36.4 per cent in South Zone (Lateef and Reed, 1983). The annual loss of pigeon pea production due to pod fly alone has been estimated to the extent of 25 to 30 per cent in U.P. (Lal and Yadav, 1987). The pod fly and pod sucking bugs are showing an increasing trend in recent years on pigeon pea and are predominant in eastern U. P. Keeping in view the above facts following investigation was carried out during kharif 2011, on seasonal incidence of tur pod fly and tur pod bug on long duration pigeon pea (Srujana, and Ram Keval, 2014). 


\section{MATERIALS AND METHODS}

The present field experiment was conducted at Entomological trial, Agricultural Research Farm, Banaras Hindu University (BHU), Varanasi during the kharif season of the year 2010-11. Pigeon pea variety UPAS120 , which is commonly cultivated in this area, was grown in plots of 5 rows, 4 meters following row to row and plant to plant spacing of $75 \mathrm{~cm}$ and $10 \mathrm{~cm}$ respectively. The crop was grown following the normal agronomic practices in "Randomized Block Design" with three replications and seven treatments.. The meteorological observations during the investigation period were recorded from the meteorological observation of the Institute of Agricultural sciences, BHU, Varanasi India.

Incidence pattern of pod fly and pod bug on short pigeon pea: For recording the seasonal incidence of Pod fly and Pod bug, five plants were selected randomly from each replication and the immature as well as the mature stages of insect-pests present on them were counted at weekly intervals, starting from first week of the October 2010 till the maturing of the crop. The insects on which the data was recorded were; $M$. obtusa and C. gibbosa. The number of insect count recorded from all the five replications for UPAS-120 genotype was averaged separately on standard week basis.

Statistical analysis: All the data recorded were subjected to statistical analysis as per the randomized block design procedure. The data of the years were subjected to the ANOVA. Analysis of Variance The mean of the larval population and pod damage of both the years were calculated and correlated with the meteorological data.

\section{RESULTS AND DISCUSSION}

Incidence pattern of pod fly: The experiment showed that the first incidence of pod fly M. obtusa maggots was observed in 42 standard weeks of 2010 (Fig.1). The maggots were recorded from 42 to 49 standard weeks. The highest mean population was observed in 45 standard weeks i.e. (0.30 maggots/plant) recorded on five plants, followed by 44 standard weeks $(0.25$ maggots/plant) on five plants and lowest population (0.02 maggots/plant), recorded in the 49 standard weeks. A similar type of result was also recorded by Yadav et al. (2011) examined the seasonal incidence of pod fly, M. obtusa on pigeon pea and revealed that maximum incidence of $M$. obtusa in terms of maggots were first observed in 40th SMW (Standard Metrological Week).

when the crop was 90 to 100 days old. Higher number of maggots occurred from 44-48 SMW, with peak (8.00 maggots/25) being in 47 th week. Number of maggots ( 0.61 maggots $/ 25$ pods) was very low in the last week of November 2003. Thus the pest remains active for nearly two months from first week of October to last week of November. Similar trends of result was also found by Subharanani and Singh (2009) reported that the pod fly incidence was noticed from the second week of January (2.0 to $2.8 \%$ ), with a peak of $15.6 \%$ in the first and $13.7 \%$ in the second year, during the third week of January. Srujana and Ram Keval (2014) also reported that the highest mean population of Pod fly, M. obtusa was observed in 9th standard week i.e., 7.0 maggots, followed by 12 th standard week 6.8 maggots and lowest population 0.8 maggots, recorded in the $1 \mathrm{st}$ standard week during kharif season of the year 201112.

Incidence pattern of pod bug: The first incidence of pod bug $C$. gibbosa adult was observed in the 40 standard weeks of the year 2010 (Fig. 1). The adult of pod bug were recorded from 40 to 50 standard weeks. The peak in the average pod bug adult population was recorded on the 44 and 45 standard weeks ( 0.40 adult / plant) followed by $42,43,46,47$, standard weeks with a population of ( 0.30 adult/plant $)$ and lowest population of pod bug was recorded in ( 0.02 adult /plant) in the 40 standard weeks of year. A similar type of result was also recorded by Srujana and Ram Keval (2014) found that the highest mean population peak of Pod bug, $C$. gibbosa was recorded on 9th standard week 6.4 bugs, followed by 8 th standard week 5.8 bugs and lowest population of 0.2 adults was recorded in the 1st standard week during kharif season of the year 2011-12. Singh and Singh (2014) reported that the pod bug activity appeared from 20th standard week, increased subsequently and reached at peak level of population density during 25th standard week during both the years i.e. zaid, 2009- 10 and 2010-11 with varying population densities. According to Niba (2011) from South Africa, pod sucking bugs entered in cowpea fields at 8 weeks after sowing (52nd standard week) and remained on the crop till harvesting. They attained peak infestation level at 12 weeks after sowing (4th standard week).Sujithra and Chander (2014) also reported that the seasonal incidence of pod bug, $C$. gibbosa on pigeon pea and revealed that maximum



Fig. 1. Mean number of M. obtusa and C. gibbosa larvae/ plant on short duration pigeon pea during rainy season of 2010. 
incidence during 2011, pod bugs were noticed from 36th to 44th SMW (Standard metrological week) and their population reached maximum of 3.47 bugs/plant during 38th to 40th SMW. Similarly, during 2012, it was found to be 3 bugs/ plant during 38th SMW. The study revealed that the activity of insect pests started during 36th standard week and continued until 46th SMW with 38th and 39th SMW being most crucial.

\section{Conclusion}

It was concluded that the first incidence of pod fly, $M$. obtusa was in $42^{\text {th }}$ standard week in 2010-11. The peak population of pod fly was recorded in 45 standard week. The first incidence of pod bug, C. gibbosa was observed in $40^{\text {th }}$ standard week in 2010-11. The peak of population of pod bug was recorded in both 44 and 45 standard week. Thus, incidence of insect-pest was increased with the advancement of crop age and the actual damage to the economic produce took place after flowering of the crop.

\section{REFERENCES}

Anonymous (2011). All India area, production and yield of pigeon pea. Agricultural statistics, Ministry of agriculture, Government of India, New Delhi.

FAO (2013). Food and Agriculture Organization of the United Nations. (2013). FAO Statistical database. http://faostat.fao.org (19 ${ }^{\text {th }}$ July 2013, date last accessed).

Lal, S.S. and Yadav, C.P. (1987). Estimates of crop losses in pigeonpea caused by the pod borer complex. FAO Plant Protection Bulletin, 35 (3): 93-98.

Lateef, S. S. and Reed, W. (1981). Survey of insect pest damage in farmer's field in India. International pigeonpea Newsletter, 1: 29-30.

Lateef, S.S. and Reed, W. (1983). Review of crop losses caused by insect pest in pigeonpea internationally and in India. In: Crop losses due to insect pests (eds. Krishnamurthy Rao, B.H. and Murthy, K.S.R.K.). Special issue of Indian Journal of Entomology, Entomological Society of
India, Hyderabad, A.P, India, pp. 284-291

Sujithra, M. and Subhash Chander (2014). Seasonal incidence and damage of major insect pests of pigeon pea, Cajanus cajan (L.), Indian Journal of Entomology, 76 (3): 202-206.

Niba, A. S. (2011). Arthropod assemblage dynamics on cowpea, Vigna unguiculata (L) Walp. in subtropical agro ecosystem, South Africa,African J. Agril. Res. 6: 10091015.

Sachan, J.N., Yadava, C.P., Ahmad, R. and Katti, G. (1994). Insect pest management in pulse crops. In Trends in Agricultural insect pest management, 308344, New Delhi (Commonwealth Publishers).

Arora, S., Iquebal, V., Rai, M.A. and Kumar. D. (2013). PIPEMicroDB: Microsatellite Database and primer generation tool for pigeonpea genome. Database, 2013 Article ID bas054, doi: 10.1093/database/bas054. (http://database.oxfordjournals.org).

Yadav, S.K., Ahuja, D.B. and Dhandapani, A. (2011). Seasonal activity of pod fly, Melanagromyza Obtusa (Malloch.) (Diptera: Agromyzidae) and effect of abiotic factors on its incidence in pigeon pea, Indian Journal of Entomology, 73(2):162-165.

Singh, C. and Singh, N. N. (2014). Occurrence of insect-pests infesting cowpea (Vigna unguiculata walpers) and their natural enemy complex in associations with weather variables, Legume Res, 37 (6): 658-664.

Subharanani, S. and Singh, T. K. (2009). Population dynamics of pod borer complex in pigeon pea in relation to abiotic factors. Indian Journal of Entomology, 71(3): 215-218.

Srujana, Y. and Ram Keval (2014). Periodic occurrence and association of pod fly and pod bug on long duration pigeon pea (bahar) with weather parameters, J. Exp. Zool. India, 17(2): 595-597.

Verma, N. U. K. (1983). Studies on insect pests of arhar Cajanas cajan Milsp. with particular reference to screening of germplasm and estimation of losses caused by pod infesting insect. M.Sc. Ag thesis, JNKVV, Jabalpur.

Durairaj, C. (2006). Evaluation of certain neem formulations and insecticides against pigeonpea podfly. Indian Journal of Pulses Research, 19 (2): 269-270. 